\title{
Cogeneration of Neurons with a Unique Molecular Phenotype in Layers V and VI of Widespread Lateral Neocortical Areas in the Rat
}

\author{
Yasuyoshi Arimatsu, Itsuko Nihonmatsu, Kanako Hirata and Keiko Takiguchi-Hayashi \\ Laboratory of Neuromorphology, Mitsubishi Kasei Institute of Life Sciences, Tokyo 194, Japan
}

\begin{abstract}
Monoclonal antibody PC3.1 detects a unique subpopulation of neurons located mainly in layer $\mathrm{VI}$ and, to a lesser extent, in layer $\mathbf{V}$ within the lateral neocortical areas in the rat. In an attempt to characterize these neurons, we determined the time of their generation in selected neocortical areas by a double-labeling experiment combining quantitative longsurvival ${ }^{3} \mathrm{H}$-thymidine autoradiography and immunohistochemistry for the PC3.1 antigen. We found that the vast majority of PC3.1-positive neurons in both layers $V$ and VI were generated concurrently at embryonic day 15 in all areas examined, demonstrating a strict correlation between the molecular identity of neurons and the time of their generation, irrespective of their final positions along the radial and tangential axes. In contrast, PC3.1-negative neurons, which should represent more diverse phenotypic identities, were generated during a more extended period of cortical development and tended to exhibit radial (inside-to-outside) and tangential (ventral-to-dorsal and rostral-to-caudal) neurogenetic gradients. Our findings indicate that laminar and tangential locations of cortical neurons are not established solely by a combination of mechanisms for the inside-out movement of newly generated neurons in each cortical area and for the broad tangential neurogenetic gradients. The results of this study suggest a distinct way of cortical development in which neurons with a common molecular phenotype are generated concurrently and migrate toward their eventual positions, which are not necessarily located in a single lamina. In addition, our results suggest some kind of tangential heterogeneity in the mechanism involved in neocortical histogenesis, supporting the concept of early regional specification within the neocortex.
\end{abstract}

[Key words: neurogenesis, neocortex, claustrum, endopiriform nucleus, regional specification, neuronal identity, neuronal migration, laminar fate, ${ }^{3} \mathrm{H}$-thymidine autoradiography, monoclonal antibody]

We have generated a monoclonal antibody, designated PC3.1, that detects a neuronal entity confined to lateral, but not dorsomedial, neocortical areas and to some other telencephalic regions in the rat (Arimatsu et al., 1992a). By using this antibody as a molecular marker, it was possible to show that a molecular phenotype restricted to the lateral neocortex is specificd early, well before thalamocortical interactions and even before cortical

\footnotetext{
Received May 11, 1993; reviced Sept. 9, 1993; accepted Sept. 21, 1993.

Correspondence should be addressed to Dr. Y. Arimatsu, Laboratory of Neuromorphology, Mitsubishi Kasei Institute of Life Sciences, 11 Minamiooya, Ma chida-shi, Tokyo 194, Japan.

Copyright 1994 Society for Neuroscience $0270-6474 / 94 / 142020-12 \$ 05.00 / 0$
}

neurogenesis. To facilitate a better understanding of molecular and cellular mechanisms underlying the early regional specification, it is important first to know about the time and site of generation of these neurons and then to investigate the way by which cortical progenitor cells are committed to the specific molecular phenotype.

Neurons in the neocortex are distributed in six laminar laycrs and, within each layer, they tend to show similar cellular identities (Gilbert, 1983). The time of their generation ("birthday") has been determined by autoradiographic detection of ${ }^{3} \mathrm{H}$-thymidine administered during the embryonic period. It has been well established that neurons of the neocortex in most mammals tend to originate in an inside-to-outside sequence (for review, see McConnell, 1988; Jacobson, 1991). Thus, earlier-generated neurons are located in a deeper layer and later-generated neurons in a more superficial layer.

Although it is possible, based on the intimate relationship between cellular identity of neurons and their laminar fate, that the relationship between the time of generation and laminar fate is controlled by factors that regulate cell fate determination, it has not yet been established to what extent linkage is present between the time of generation and a specific cell's fate, either for morphological, connectional, or molecular phenotypes. Since the PC3.1-positive neurons are located in different deep layers in the neocortex (Arimatsu et al., 1992a), it would be possible to examine whether a strict linkage is indeed present between the time of their generation and the molecular phenotype, by comparing the time of generation in the different laminae.

Previous ${ }^{3} \mathrm{H}$-thymidine birth-dating studies have also demonstrated tangential neurogenetic gradients when dealing with neocortical neurons as a single population. Thus, neurons in rostral and ventral regions in the neocortex tend to originate carlier than those in caudal and dorsal regions, respectivcly. It is not known, however, whether these general tangential gradients apply to each particular neuronal phenotype. Since PC3.1positive neurons are distributed across widespread lateral neocortical regions, it would also be possible to address this question by examining the time of generation along the rostral-caudal and ventral-dorsal axes.

We have previously shown that PC3.1-positive neurons in layer VI of the parietal cortex, area 2 (Par2; = secondary somatosensory area) are generated around embryonic day 15 (E15; Arimatsu et al., 1992a). The primary purpose of the present study was to expand upon the previous experiment and to investigate the time of generation of PC 3.1-positive neurons in different deep laminae of various latcral ncocortical areas in the rat. The time of generation of PC3.1-positive neurons in some extraneocortical regions was also examined and compared with that of neocortical neurons. 
Part of this work has been presented in an abstract form (Arimatsu et al., 1992b).

\section{Materials and Methods}

Experimental animals. Rats of Wistar strain were maintained under constant photoperiods ( $12 \mathrm{hr}$ light $/ 12 \mathrm{hr}$ dark; light on at 9:00 A.M.). Pregnant rats were obtained by overnight mating. The day when a vaginal plug was observed in the morning was designated embryonic day 0 (E0). Birth usually occurred late on E21 (=postnatal day 0, P0).

Immunohistochemistry. The rats were deeply anesthetized with ether and fixed by cardiac perfusion with $4 \%$ paraformaldehyde in $0.1 \mathrm{M}$ sodium phosphate buffer $(\mathrm{pH} 7.4)$. Their brains were removed and fixed further by immersion in the same fixative $\left(4^{\circ} \mathrm{C}, 7 \mathrm{hr}\right)$. Each block of brain was equilibrated in $30 \%$ sucrose in phosphate-buffered saline (PBS; $\mathrm{pH} 7.4$ ), frozen in OCT compound (Lab-Tek), and serial coronal sections were cut on a cryostat at $10 \mu \mathrm{m}$ intervals. The sections were mounted onto gelatin/chrome alum-subbed glass slides and incubated sequentially with $5 \%$ normal goat serum in PBS containing $0.1 \%$ Triton X-100 (5NGS/T; $20 \mathrm{~min}), \mathrm{PC} 3.1$ monoclonal antibody $(13 \mu \mathrm{g} / \mathrm{ml}$ in $5 \mathrm{NGS} /$ $\mathrm{T}, 2 \mathrm{hr}$ ), goat anti-mouse IgG (Cappel; $1: 50$ dilution in $5 \mathrm{NGS} / \mathrm{T}, 2 \mathrm{hr}$ ), and mouse peroxidase-antiperoxidase (PAP; Jackson; 1:500 dilution in $5 \mathrm{NGS} / \mathrm{T}, 1 \mathrm{hr}$ ). The bound antibody was visualized by incubating the sections with $0.02 \% 3,3^{\prime}$-diaminobenzidine and $0.01 \% \mathrm{H}_{2} \mathrm{O}_{2}$ in $50 \mathrm{~mm}$ Tris- $\mathrm{HCl}, \mathrm{pH} 7.6(20 \mathrm{~min})$. After rinsing in distilled water the sections were treated with $0.01 \% \mathrm{OsO}_{4}$ to intensify the staining.

Estimation of time of neuronal generation. Timed-pregnant rats were injected intraperitoneally at 2:00 P.M. with ${ }^{3} \mathrm{H}$-thymidine (New England Nuclear; $6.7 \mathrm{Ci} / \mathrm{mmol}, 1 \mathrm{Ci}=37 \mathrm{GBq} ; 0.5 \mathrm{mCi} / 100 \mathrm{gm}$ body weight). The delivered pups were killed at P42, and cryostat sections of their brains were processed for immunohistochemical visualization of PC3.1antigen with PAP as described above. The animals used in the present study are listed in Table 1. For each brain, 1 in 10 sections was dehydrated with sequential incubation in a series of ethanol $(70-100 \%)$, defatted in xylene ( $2 \mathrm{hr}$ ), and rehydrated in the same ethanol series down to water. The sections were air dried, dipped into autoradiographic emulsion NR-M2 (Konica; diluted with an equal volume of distilled water) at $43^{\circ} \mathrm{C}$, and air dried. They were exposed in a desiccating box $\left(4^{\circ} \mathrm{C}, 4\right.$ weeks $)$, developed with Konicadol-X $\left(20^{\circ} \mathrm{C}, 4 \mathrm{~min}\right)$, and fixed with Konicafix $\left(20^{\circ} \mathrm{C}, 5 \mathrm{~min}\right)$. A series of sections adjacent to those used for the double labeling was stained with cresyl violet.

To estimate the time of generation of PC3.1-positive neurons, the autoradiographic signal was quantified by using a Vidas image analysis system (Zeiss/Kontron) equipped with a light microscope (Zeiss Axioscop) with a motor-driven scanning stage. At first, the image of a lowpower view of a section was transferred to the screen of a video monitor at a $5 \times$ objective and a scanning area was outlincd interactively. Then, using a $40 \times$ objective, positions of PC3.1-positive neurons were stored in a data file by marking the neurons interactively. Finally, using a $100 \mathrm{x}$ objective, the number of autoradiographic silver grains was counted interactively over the nucleus of a PC3.1-positive neuron on the screen. The scanning stage moved automatically to the next registered position after each counting. The number of silver grains over PC3.1-negative neurons was also counted. Positions of clusters of from medium to large numbers of silver grains (approximately 20 or more) were identified on the screen at the $40 \times$ objective and exact grain counting was then performed using the $100 \times$ objective as described above.

\section{Results}

Distribution of PC3.1-positive structures in the forebrain

Monoclonal antibody PC3.1 recognized a neuronal subpopulation located in a lateral sector of the neocortex (Arimatsu et al., 1992a). This included the parietal cortex, area 2 (Par2; Figs. $1 A, 2 B, 3 A-D$ ), visceral sensory area (Vi; Fig. $2 A$ ), temporal cortex, area 1 (Te1; Fig. $2 C$ ), area 2 (Te2; Fig. $2 D$ ), and area 3 (Te3; Figs. $2 E, 3 E, F$ ), and occipital cortex area 2, lateral (Oc2L; Figs. $2 F, 3 G)$. Immunopositive neurons were also found in the lateral periallocortex including the agranular insular (AI; Fig. $4 A$ ), lateral orbital (not shown), and perirhinal (not shown) areas, in the claustrum (Cl; Fig. $4 A$ ) and in the dorsal and ventral endopiriform nuclei (DEn and VEn; Fig. 4 $A$ ). There were some PC3.1-positive neurons in the presubiculum as well (not shown).
Table 1. Number of animals used in a double-labeling experiment for PC3.1 immunoreactivity and ${ }^{3} \mathrm{H}$-thymidine incorporation

\begin{tabular}{lll}
$\begin{array}{l}\text { Day of injection } \\
\text { of }{ }^{3} \text { H-thymidine }\end{array}$ & $\begin{array}{l}\text { Number of mothers } \\
\text { injected with } \\
{ }^{3} \text { H-thymidinc }\end{array}$ & $\begin{array}{l}\text { Number of pups } \\
\text { used for double- } \\
\text { labeling } \\
\text { cxpcriment }^{a}\end{array}$ \\
\hline E11 & 1 & $2(1)$ \\
E12 & 2 & $4(4)$ \\
E13 & 2 & $4(4)$ \\
E14 & 2 & $4(1)$ \\
E15 & 3 & $6(4)$ \\
E16 & 2 & $4(2)$ \\
E17 & 1 & $2(1)$ \\
E18 & 1 & $2(1)$ \\
\hline
\end{tabular}

a The sex of the experimental animals was chosen randomly. The number of male rats in each injection group is shown in parentheses.

To estimate the relative laminar density of PC3.1-positive neurons, we counted the number of PC3.1-positive neurons in separate layers of selected neocortical areas (Table 2). The majority of them (68-91\%) were found in layer VI in all areas examined. In Vi and Par2 more PC3.1-positive neurons were found in the lower part of layer VI than in the upper one, but in other areas this tendency was not evident (Fig. 2). Substantial numbers of PC3.1-positive neurons, although to a lesser extent, were found also in layer $\mathrm{V}(7-29 \%)$. The positive neurons were found at various depths of layer $\mathrm{V}$ and did not show any tendency to be located near the border with layer VI (see Fig. $2 B, D, E)$. PC3.1-positive neurons in the upper layers or in the white matter were very low in number $(<3 \%$; Fig. $3 D)$.

Although the morphological characteristics of PC3.1-positive neurons were not determined in detail in the present study, many of them were pyramidal, multipolar, or bipolar in shape (Fig. 3). We frequently observed PC3.1-positive neurons which resembled "atypically oriented" or "inverted" pyramidal cells (Miller, 1988a; Bueno-López et al., 1991) with their apical dendrite extending toward various directions (toward the white matter, and parallel or oblique to the white matter; see Fig. 3) as well as "typical" pyramidal cells with their apical dendrites toward the pia matter.

In addition to that of the neuronal cell bodies and dendrites, immunostaining was observed in some other neural structures. Although most of the fiber tracts in the forebrain were not PC3.1 immunopositive, some axon fibers in the cortical white matter (Figs. $2 A, 3 D$ ) and the fornix (not shown) were substantially immunostained. The PC3.1-positive axon fibers were especially evident at the rustrocaudal level near $\mathrm{Cl}$ where both neuronal cell bodies and the neuropil were strongly immunostained (Fig. 4). This may suggest the presence of PC3.1-positive claustrocortical and/or corticoclaustral axon fibers, although a definite conclusion on this point remains to be determined. In some regions (e.g., the mammillary body and basolateral amygdaloid nucleus), from weak to moderate staining was seen in the neuropil. In the neocortex, weak neuropil staining was seen in layer IV and other layers (see Fig. $1 A$ ), even in regions without PC3.1positive neuronal cell bodies. In most of the forebrain structures, including the neocortex, hippocampus, amygdala, caudate putamen, olfactory bulb, hypothalamus, and thalamus, weakly stained astroglial cells were seen (Fig. $3 H$ ). 
Figure 1. Distribution of PC3.1-immunopositive cells in the parietal cortex, area 2 (Par2). A, A coronal section of a rat brain through Par2 stained with PC3.1 monoclonal antibody. $B$, An adjacent section stained with cresyl violet. Roman numerals in Figures 1 and 2 indicate cortical layers. $C P u$, caudate putamen; $W M$, white matter. In the present study, areal and laminar boundaries of the cortex were determined according to Paxinos and Watson (1986), Zilles $(1985,1990)$, and Zilles et al. (1990). Scale bar, $100 \mu \mathrm{m}$.
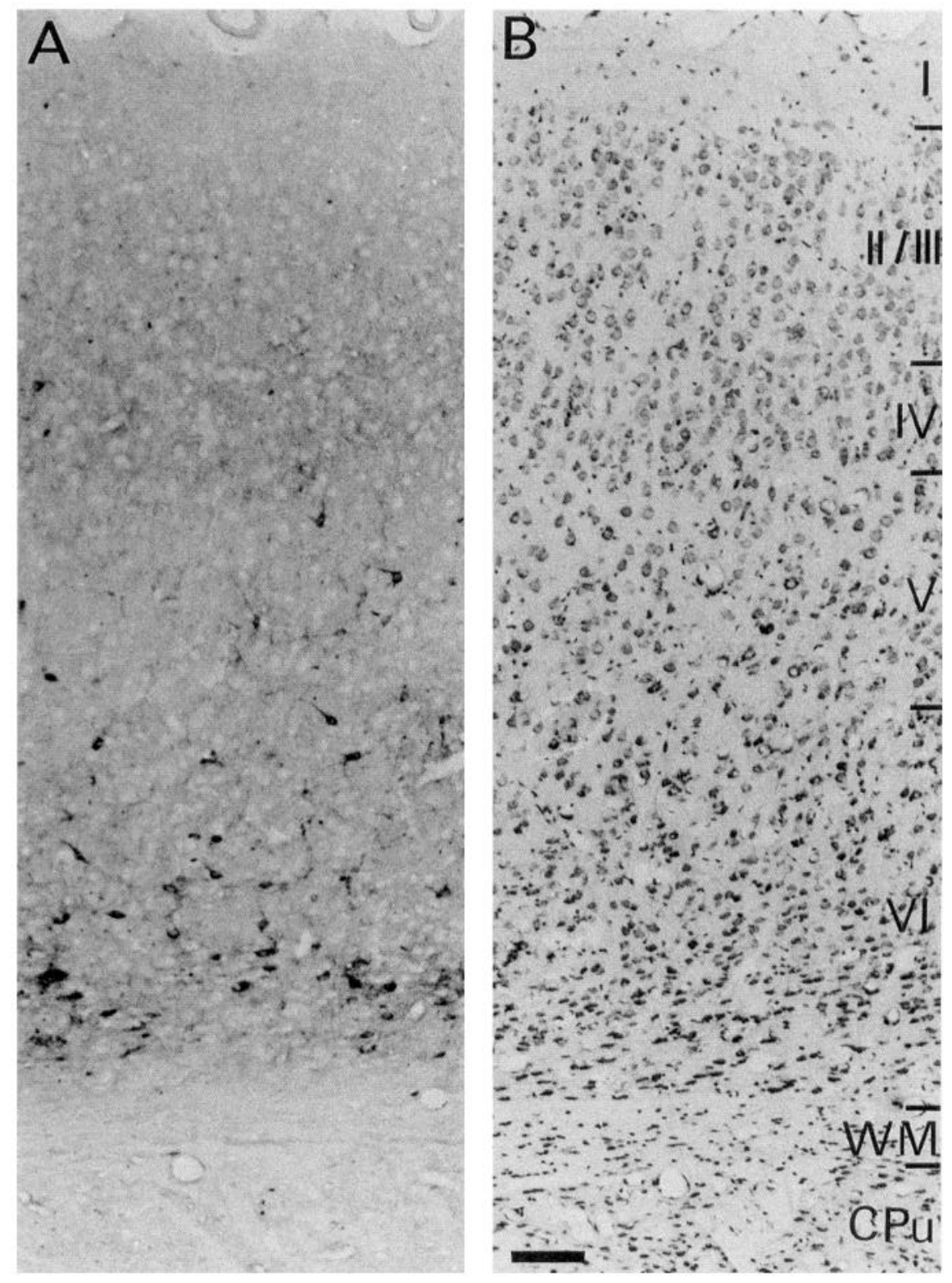

Time of generation of PC3.1-positive and-negative neurons in the neocortex

The time of generation was estimated separately for PC3.1positive and -negative neurons by a double-labeling experiment combining immunohistochemistry for PC3.1-antigen and ${ }^{3} \mathrm{H}$ thymidine autoradiography (Fig. 5). Within the neocortex, the time of generation was analyzed in five selected areas, the approximate locations of which are shown in Figure 6. We considered a neuron as being heavily labeled when the number of autoradiographic silver grains was 40 or greater. This criterion was based on the observation that the maximum number of silver grains was 159 (see Fig. 7 for relative frequency of the number of silver grains on a single cell). Any cells with more than half the maximum number of silver grains can be considered as ones that underwent only one round of DNA synthesis and cell division following the injection of ${ }^{3} \mathrm{H}$-thymidine (Sidman, 1970; Rakic, 1974), and cells with more than one-fourth of the maximum should not have divided more than twice.
When assuming that the generation time of cortical neurons is 11-19 hr (Waechter and Jaensch, 1972), and that the number of silver grains in many cells should have been underestimated due to various factors including the timing of the ${ }^{3} \mathrm{H}$-thymidine injection during their cell cycle and the variation of nuclear size and the site of sectioning within the nucleus (for detailed discussion, see Hicks and D'Amato, 1968; Sidman, 1970; Bayer and Altman, 1991a), a neuron with more than one-fourth of the maximum number of grains is most likely to have been generated within $24 \mathrm{hr}$ following the injection of ${ }^{3} \mathrm{H}$-thymidine (Cavanagh and Parnavelas, 1988, 1990). We therefore determined the percentage of the heavily labeled cells (with at least 40 grains) for each injection group for estimation of relative proportion of neurons originating within $24 \mathrm{hr}$ following the injection. Since heavily labeled neurons were found in injection groups between E12 and E17 but not in animals injected at either E11 or E18, most, if not all, of the PC3.1-positive neurons should have been generated between E12 and E17. Thus, we estimated the proportion of PC3.1-positive neurons originating 

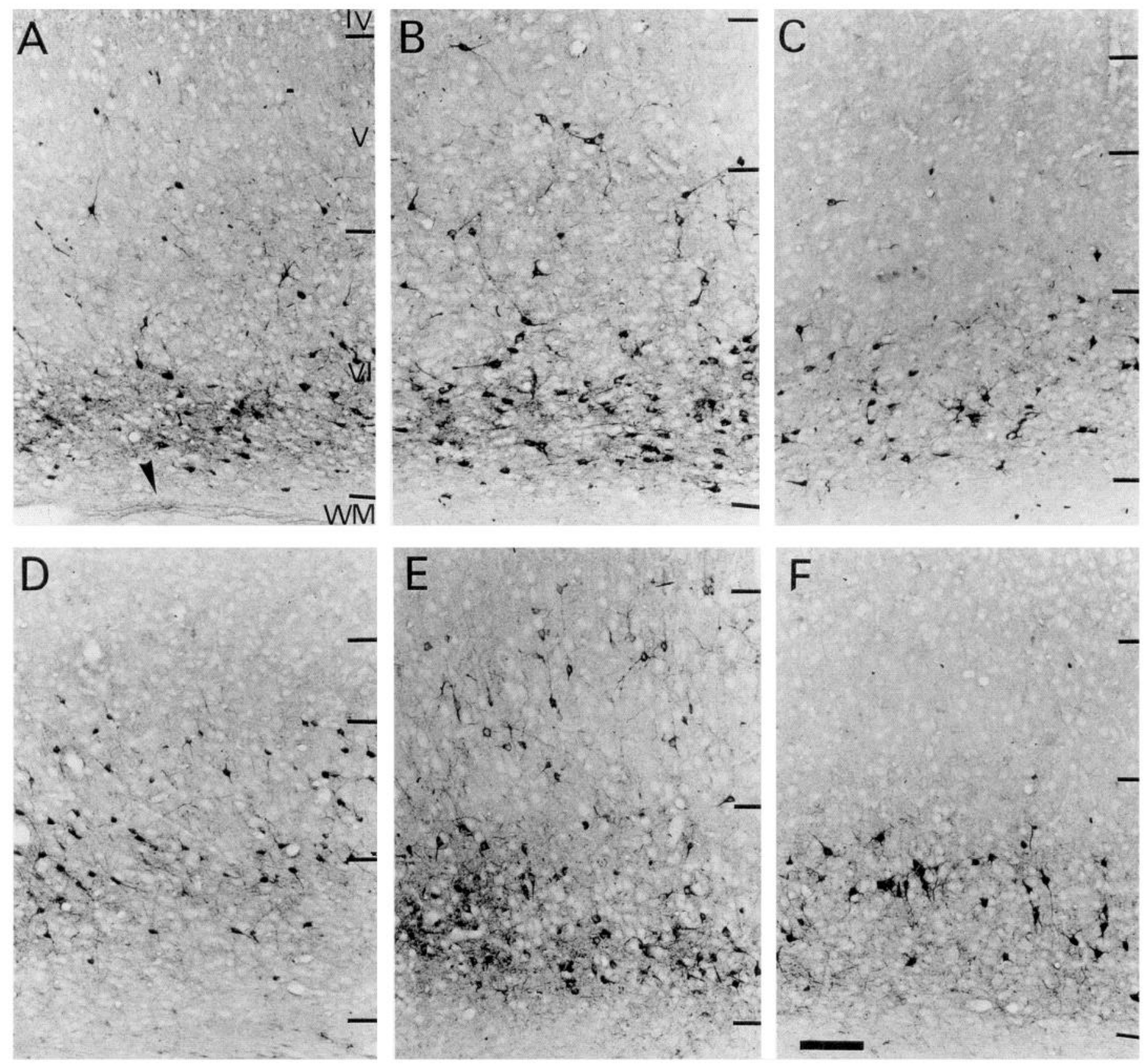

Figure 2. Distribution of PC3.1-positive cells in various lateral neocortical areas. A, Visceral sensory area (Vi). B, Parietal cortex, area 2 (Par2). $C$, Temporal cortex, area 1 (Te1). D. Temporal cortex, area 2 (Te2). E, Temporal cortex, area 3 (Te3). $F$, Occipital cortex, area 2, lateral (Oc2L). The arrowhead in $A$ indicates PC3.1-positive axon fibers. Scale bar, $50 \mu \mathrm{m}$.

on a particular day by dividing the percentage of heavily labeled neurons for each injection group by the sum of the percentages obtained between E12 and E17 (Table 3). The proportion of PC3.1-negative neurons originating was calculated by dividing the density of heavily labeled neurons for each injection group by the sum of the densities obtained between E12 and E17 (Table 4).

Time of generation of neurons in different neocortical laminae. In Te 3 and Par2, the time of generation of PC3.1-positive neurons was compared between layers V and VI. In both areas, either in layer V or in layer VI, the vast majority of PC3.1positive neurons were generated concurrently at E15 (Fig. 8A,B). In contrast, $\mathrm{PC} 3.1$-negative neurons in layers $\mathrm{V}$ and $\mathrm{VI}$ were generated in an inside-to-outside sequence in both Tè 3 and Par2 (Fig. $8 C, D$ ).

Time of generation of neurons in different neocortical areas. To compare the time of generation of PC3.1-positive neurons across widespread lateral neocortical areas, the percentage of PC3.1-positive neurons with heavy ${ }^{3} \mathrm{H}$-thymidine labeling was examined in layer VI of three additional areas $(\mathrm{Vi}, \mathrm{Te} 1$, and Oc2L) and the data were combined with those described above. As shown in Figure 9, the proportion of PC3.1-positive neurons originating was at its highest level at E15 for all five areas examined, whereas PC3.1-negative neurons in the same layer tended to show rostral-to-caudal and lateral-to-dorsal neurogenetic gradients. The peak day of neurogenesis for PC3.1-neg- 

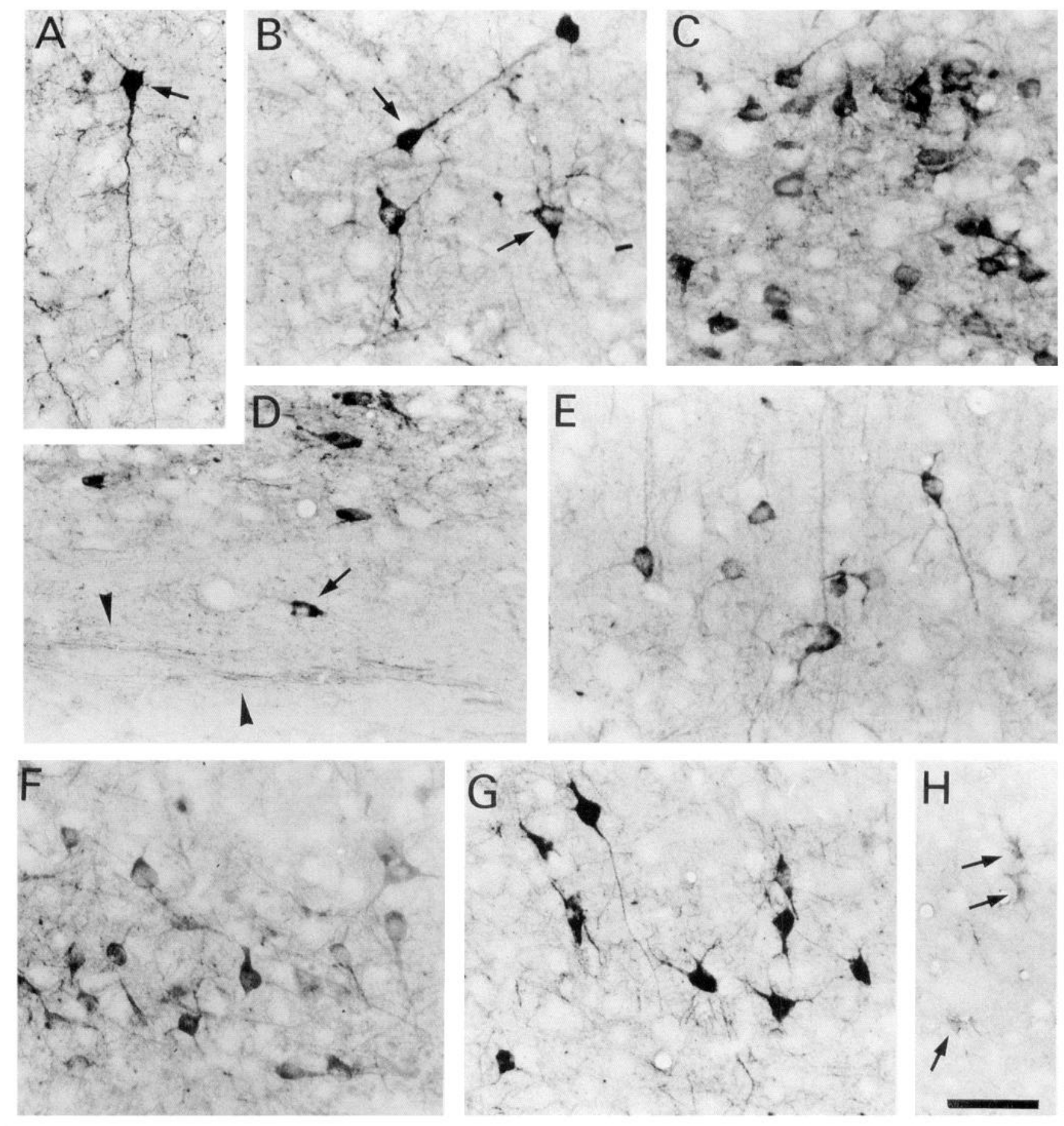

Figure 3. Higher magnification of PC3.1-positive cells. A, Par2, upper layer VI. An arrow indicates an inverted pyramidal cell. B, Par2, upper layer VI. Arrows indicate atypically oriented pyramidal cells. $C$, Par2, lower layer VI. D, Par2, bottom of layer VI and the white matter. The arrow and arrowheads indicate a PC3.1-positive neuron and PC3.1-positive fibers, respectively, in the white matter. E, Te3, layer V. F, Te3, layer VI. $G$, Oc2L, layer VI. H, Caudate putamen. Arrows indicate weakly stained astrocytes. In A-G, the top of each photomicrograph corresponds to the upper side of the neocortex (side of the pia mater). Scale bar, $50 \mu \mathrm{m}$.

Figure 4. Distribution of PC3.1-immunopositive cells in the claustrum $(C l)$, endopiriform nuclei $(E n)$, and agranular insular cortex $(A I)$. A coronal section of a rat brain stained with PC3.1 monoclonal antibody $(A)$ and its adjacent section stained with cresyl violet $(B)$ are shown. $C P u$, caudate putamen; $D E n$, dorsal endopiriform nucleus; Pir, piriform cortex; VEn, ventral endopiriform nucleus. $\mathrm{PC} 3.1$-positive neurons in $\mathrm{Cl}$ and those in the lateral part of DEn at a higher magnification are shown in insets of $A$. Scale bars: $A$ and $B, 100 \mu \mathrm{m} ;$ inset, $50 \mu \mathrm{m}$. 

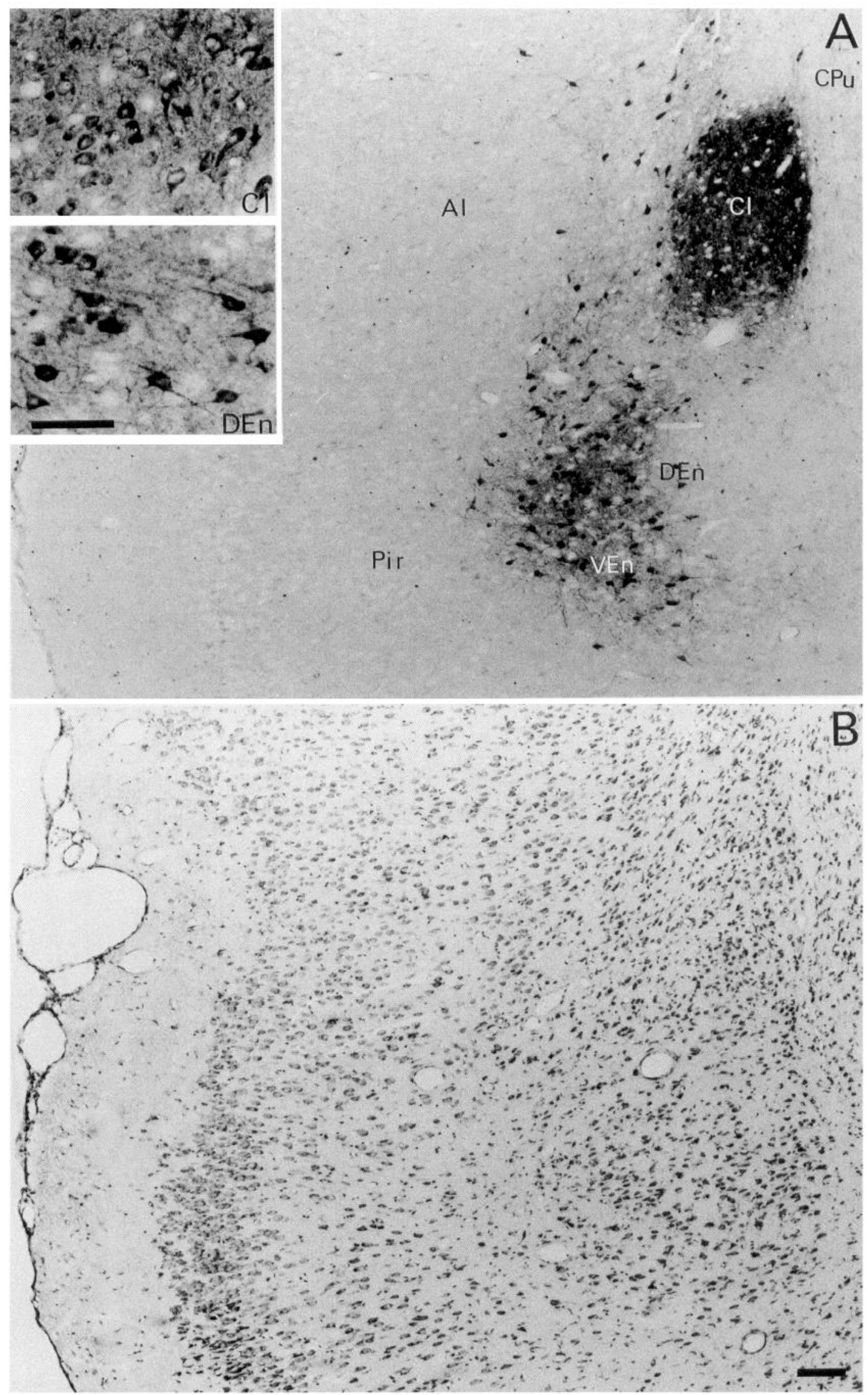
Table 2. Laminar density of PC3.1-positive neurons in lateral neocortical areas ${ }^{a}$

\begin{tabular}{llcccc} 
Lamina & Vi & Par2 & Te1 & Te3 & Oc2L \\
\hline Layer II/III, IV & $0.6 \pm 0.2(2.0 \%)$ & $0.8 \pm 0.3(1.3 \%)$ & $0.9 \pm 0.3(2.8 \%)$ & $1.1 \pm 0.3(2.3 \%)$ & $0.0 \pm 0.0(0.0 \%)$ \\
Layer V & $1.9 \pm 0.3(6.6 \%)$ & $5.7 \pm 0.9(9.3 \%)$ & $3.0 \pm 0.3(9.3 \%)$ & $13.9 \pm 1.0(29.4 \%)$ & $1.6 \pm 0.2(9.2 \%)$ \\
Layer VI & $26.5 \pm 1.2(91.4 \%)$ & $53.7 \pm 2.4(88.1 \%)$ & $28.3 \pm 2.2(87.9 \%)$ & $32.1 \pm 3.3(67.9 \%)$ & $15.7 \pm 1.2(90.8 \%)$ \\
White matter & $\mathrm{ND}^{b}$ & $0.8 \pm 0.2(1.3 \%)$ & $0.0 \pm 0.0(0.0 \%)$ & $0.2 \pm 0.1(0.4 \%)$ & $0.0 \pm 0.0(0.0 \%)$ \\
Total & $29.0 \pm 1.3$ & $61.0 \pm 2.6$ & $32.2 \pm 2.3$ & $47.3 \pm 3.8$ & $17.3 \pm 1.2$
\end{tabular}

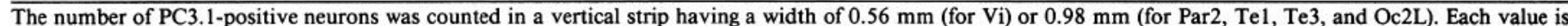
normalized to represent cell number per 0.5 -mm-wide cortical strip (mean $\pm \mathrm{SEM}, n=12$ ).

"The relative laminar density is shown in the parentheses.

"Since the white matter in the Vi region is very thin, the number of PC3.1-positive neurons was not determined (ND).

ative neurons was at E13-E14 for Vi, at E14 for Par2 and Te3, and at $\mathrm{E} 15$ for $\mathrm{Te} 1$ and $\mathrm{Oc} 2 \mathrm{~L}$. The total generation time for PC3.1-positive neurons was shorter than that for PC3.1-negative neurons. Thus, PC3.1-positive neurons in layer VI were generated within $4 \mathrm{~d}$ whereas PC3.1-negative neurons emerged throughout $5 \mathrm{~d}$. About $60 \%$ (55-64\%) of the PC3.1-positive neurons in layer VI were generated at E15 while only about $45 \%$ (42-50\%) of the PC3.1-negative neurons in the same layer appeared at the peak day of their generation.

\section{Time of generation of PC3.1-positive neurons outside the neocortex}

The time of generation of $\mathrm{PC} 3.1$-positive neurons in $\mathrm{Cl}$ and of those in the endopiriform nuclei (En; =DEn + VEn) was examined at the level shown in Figure 6 (between bregma -0.92 $\mathrm{mm}$ and bregma $-0.32 \mathrm{~mm}$; Paxinos and Watson, 1986). The majority of PC3.1-positive neurons in these regions were generated earlier than those in the neocortex. The proportion of neurons originating was at its highest level at $\mathrm{E} 14$ for $\mathrm{Cl}$ and at E13-E14 for En (Fig. 10).

\section{Discussion}

In the rat neocortex, PC3.1-positive neurons have been found only in lateral (but not dorsomedial) areas (Arimatsu et al., 1992a). In the present study, we quantitatively showed that while the majority (68-91\%) of PC3.1-positive neurons in the neocortex were located in layer VI, substantial portions (7-29\%) were found in layer V. We demonstrated that neocortical PC3.1positive neurons were generated concurrently, irrespective of their eventual positions along the radial and tangential axes.

\section{Cogeneration of neocortical PC3.1-positive neurons in layers $V$ and $V I$}

It has been established that there is a fairly strong correlation between the laminar fate of neurons and the time of their generation in the neocortex of various species (Angevine and Sidman, 1961; Berry and Rogers, 1965; Hicks and d'Amato, 1968; Shimada and Langman, 1970; Rakic, 1974; Bruckner et al., 1976; Bayer and Altman, 1991a). Thus, earlier-generated neurons tend to be located in a deeper layer and later-generated
Figure 5. Double labeling for PC3.1immunoreactivity and ${ }^{3} \mathrm{H}$-thymidine incorporation. This is a section through the Oc2L of a rat injected with ${ }^{3} \mathrm{H}$-thymidine at E15. Cells $1-3$ are positive for PC3.1. Cell 1 is moderately labeled for ${ }^{3} \mathrm{H}$-thymidine incorporation (number of silver grains, 36 ). Cell 2 is heavily labeled (number of silver grains, 79). Cell 2 is not labeled above the background level. Arrowheads indicate clusters of silver grains on PC3.1-negative neurons. Scale bar, $20 \mu \mathrm{m}$.

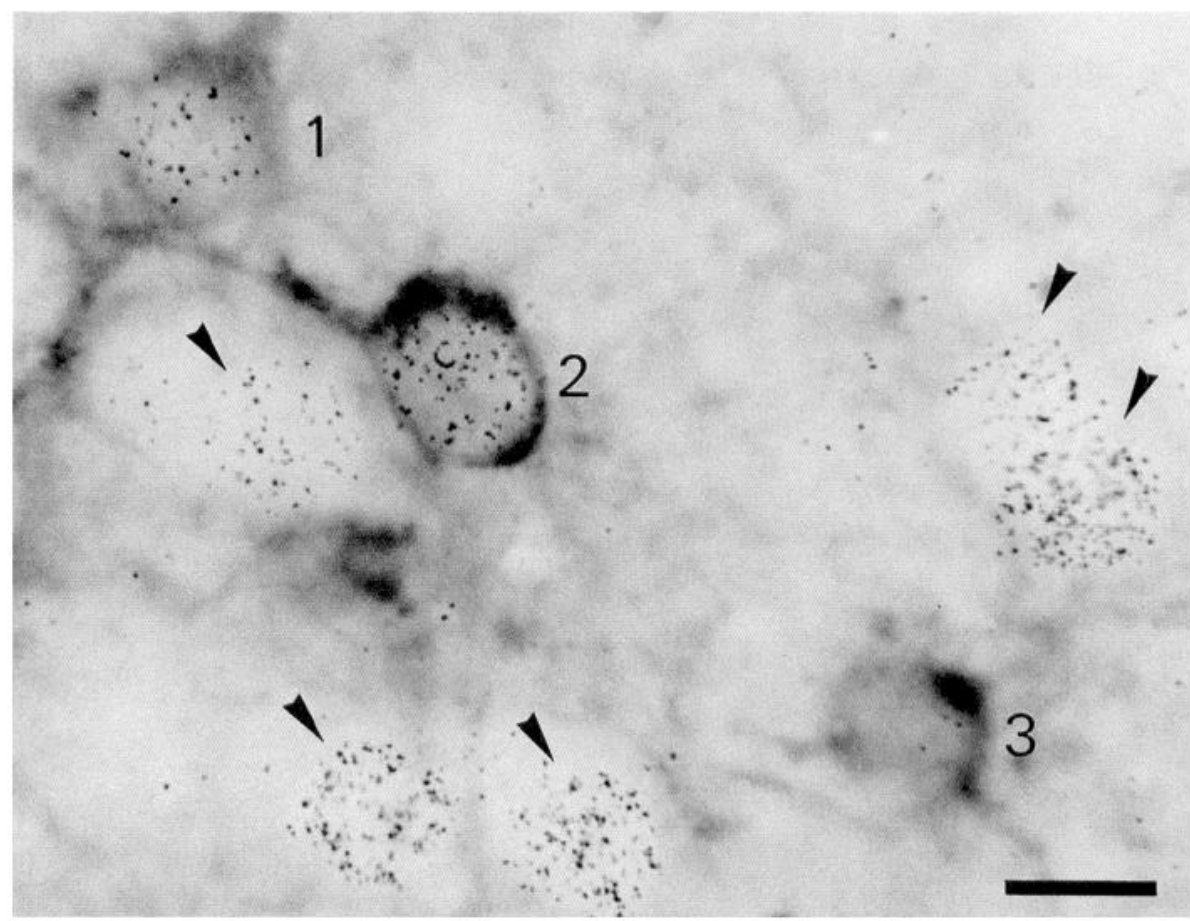




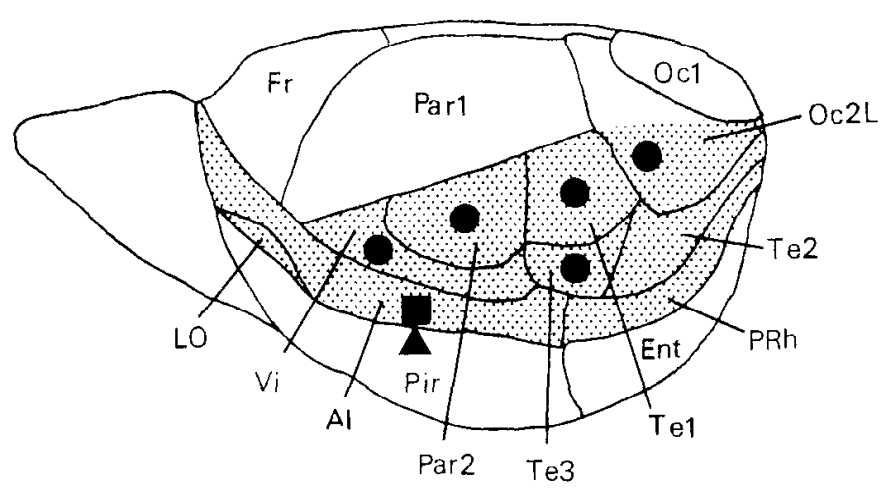

Figure 6. Schematic illustration of a lateral surface view of the rat forebrain showing cortical areas containing PC3.1-positive neurons (shaded). Approximate locations at which neurogenesis was analyzed are shown by solid circles (for neocortical areas), a rectangle (for $\mathrm{Cl}$ ), and a triangle (for Fn). Ent, entorhinal cortex; Fr, frontal cortex; $L O$. lateral orbital cortex; $O \subset 1$, Occipital cortex, area 1; Parl, parictal cortex, area $1 ; P R h$, perirhinal cortex.

neurons in a more superficial layer. The exceptions are the neurons in layer I, which are generated during the earliest phase of neocortical development. There is, however, substantial radial spread of simultaneously generated neurons. In the rat Par2; for example, the majority of neurons generated at $\mathrm{E} 14$ are destined to settle in layer VI but others are found in layer V, while most neurons generated at $\mathrm{E} 15$ are in layer $\mathrm{V}$ and, to a lesser extent, in layers IV and VI (Bayer and Altman, 1991a). The radial spread has also been observed in other species (monkey, Rakic, 1974; cat, Luskin and Shatz, 1985; ferret, Jackson et al., 1989; hamster, Lent et al., 1990). The present study revealed that the vast majority of PC3.1-positive neurons in either layer $\mathrm{V}$ or layer VI are generated concurrently at E15, indicating that the birthday of neurons is linked more strictly with the phenotypic

\begin{tabular}{|c|c|c|c|c|}
\hline $\begin{array}{l}\text { Embryonic } \\
\text { day }\end{array}$ & Layer & $\begin{array}{l}\text { Number of } \\
\text { sections } \\
\text { observed }\end{array}$ & $\begin{array}{l}\% \text { Heavily } \\
\text { labeled cells }\end{array}$ & $\begin{array}{l}\% \text { Cells } \\
\text { originating }\end{array}$ \\
\hline \multirow[t]{2}{*}{ E11 } & v & 4 & $0.0(107)$ & 0.0 \\
\hline & VI & 4 & $0.0(250)$ & 0.0 \\
\hline \multirow[t]{2}{*}{ E12 } & $\mathrm{V}$ & 12 & $0.0(210)$ & 0.0 \\
\hline & $\mathrm{VI}$ & 8 & $0.0(395)$ & 0.0 \\
\hline \multirow[t]{2}{*}{ E13 } & $\mathrm{V}$ & 11 & $0.0(231)$ & 0.0 \\
\hline & VI & 8 & $1.6(371)$ & 4.6 \\
\hline \multirow[t]{2}{*}{ E14 } & $\mathrm{V}$ & 12 & $2.5(283)$ & 7.2 \\
\hline & VI & 8 & $3.1(360)$ & 8.8 \\
\hline \multirow[t]{2}{*}{ E15 } & $\mathrm{v}$ & 19 & $24.1(514)$ & 70.3 \\
\hline & VI & 13 & $21.0(685)$ & 60.2 \\
\hline \multirow[t]{2}{*}{ E16 } & $\mathrm{V}$ & 12 & $7.7(285)$ & 22.5 \\
\hline & VI & 8 & $9.2(445)$ & 26.4 \\
\hline \multirow[t]{2}{*}{ E17 } & $\mathrm{V}$ & 6 & $0.0(156)$ & 0.0 \\
\hline & VI & 4 & $0.0(255)$ & 0.0 \\
\hline \multirow[t]{2}{*}{ E18 } & $\mathrm{V}$ & 4 & $0.0(111)$ & 0.0 \\
\hline & VI & 4 & $0.0(299)$ & 0.0 \\
\hline
\end{tabular}

The number of PC3.1-positive neurons with heavy ${ }^{3} \mathrm{H}$-1hymidine labeling was examined in 0.98 -mm-wide vertical strips of Te3. The percentage of cells originating at cach embryonic day was calculated by dividing percentage of heavily labeled cells in each injection group by the sum of percentages obtained between $\mathrm{E} 12$ and $\mathrm{E} 17$ ( $34,3 \%$ for layer V, 34.9\% for layer VI).

a The total number of PC 3.1 -positive cells counted is shown in the parentheses.

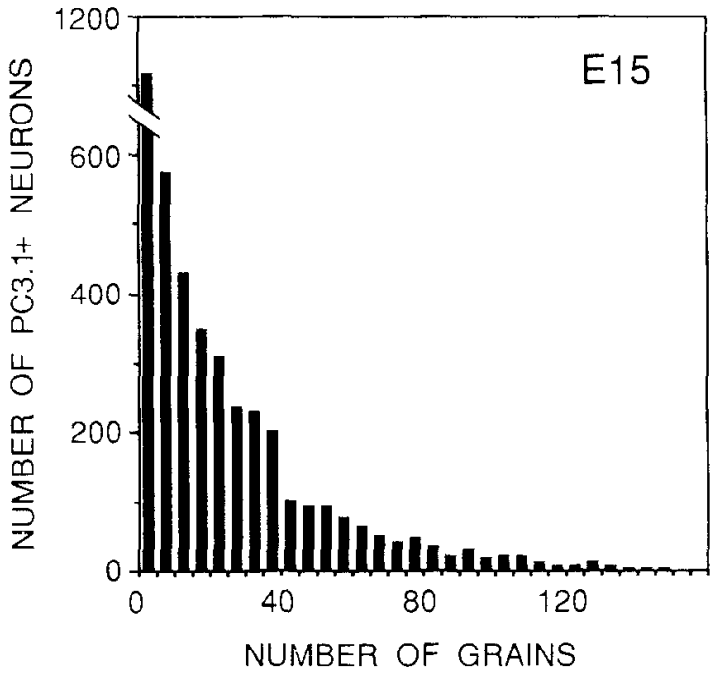

Figure 7. Number of autoradiographic silver grains on single PC3. Ipositive neurons. Each value represents the frequency of occurrence of PC3.1-positive neurons with the number of silver grains indicated on the ahscissa $(0-4,5-9,10-14, \ldots, 155-159)$. The data were derived from 4217 PC3.1-positive neurons in 110 neocortical sections from a total of six rats that had received ${ }^{3} \mathrm{H}$-thymidine at E15.

identity rather than the laminar position in the adult. It is possible to speculate that neurons with heterogeneous birthdays in a particular lamina represent, at least in part, certain diverse phenotypic populations, each of which are generated concurrently. The radial spread of each population with a single birthday might vary from one to another, thus contributing to the extent of the radial migratory spread in general. This view is in accordance with the observation that, even within a single layer,

Table 4. Neurogenesis of PC3.1-negative neurons in Te3

\begin{tabular}{|c|c|c|c|c|}
\hline $\begin{array}{l}\text { Embry- } \\
\text { onic } \\
\text { day }\end{array}$ & Layer & $\begin{array}{l}\text { Number of } \\
\text { sections } \\
\text { observed }\end{array}$ & $\begin{array}{l}\text { Number of } \\
\text { heavily labeled } \\
\text { cells per } 0.1 \\
\text { mm }^{? a}\end{array}$ & $\begin{array}{l}\% \text { Cells } \\
\text { origi- } \\
\text { nating }\end{array}$ \\
\hline \multirow[t]{2}{*}{ E11 } & $\mathrm{V}$ & 4 & $0.0(0.94)$ & 0.0 \\
\hline & $\mathrm{VI}$ & 4 & $0.0(1.10)$ & 0.0 \\
\hline \multirow[t]{2}{*}{ E 12} & $\mathrm{~V}$ & 8 & $0.0(1.81)$ & 0.0 \\
\hline & VI & 8 & $0.8(2.09)$ & 1.9 \\
\hline \multirow[t]{2}{*}{ E13 } & $\mathrm{V}$ & 8 & $1.1(1.80)$ & 4.0 \\
\hline & VI & 8 & $10.7(1.97)$ & 25.4 \\
\hline \multirow[t]{2}{*}{ E14 } & $\mathrm{V}$ & 8 & $7.4(1.58)$ & 26.1 \\
\hline & VI & 8 & $20.9(1.93)$ & 49.7 \\
\hline \multirow[t]{2}{*}{ E15 } & $\mathrm{V}$ & 12 & $15.3(2.77)$ & 53.8 \\
\hline & VI & 13 & $7.7(3.18)$ & 18.4 \\
\hline \multirow[t]{2}{*}{ E 16} & V & 8 & $4.5(1.73)$ & 15.7 \\
\hline & VI & 8 & $2.0(2.14)$ & 4.7 \\
\hline \multirow[t]{2}{*}{ E17 } & $\mathrm{V}$ & 4 & $0.1(0.90)$ & 0.4 \\
\hline & VI & 4 & $0.0(1.12)$ & 0.0 \\
\hline \multirow[t]{2}{*}{ E18 } & $\mathrm{V}$ & 4 & $0.0(0.94)$ & 0.0 \\
\hline & VI & 4 & $0.0(1.13)$ & 0.0 \\
\hline
\end{tabular}

The number of $\mathrm{PC} 3$.1-negative cells with heavy ${ }^{3} \mathrm{H}$-thymidine labeling was $\mathrm{cx}$ amined in an area of $0.15-0.28 \mathrm{~mm}^{2}$ per section. The percentage of cells originating at each embryonic day was calculated by dividing the number of heavily labeled cells in each injection group by the sum of the number obtained between E12 and E1) (28.4 for layer $\mathrm{V}, 42.1$ for layer $\mathrm{VI})$.

The total area $\left(\mathrm{mm}^{2}\right)$ examined is shown in the parentheses. 

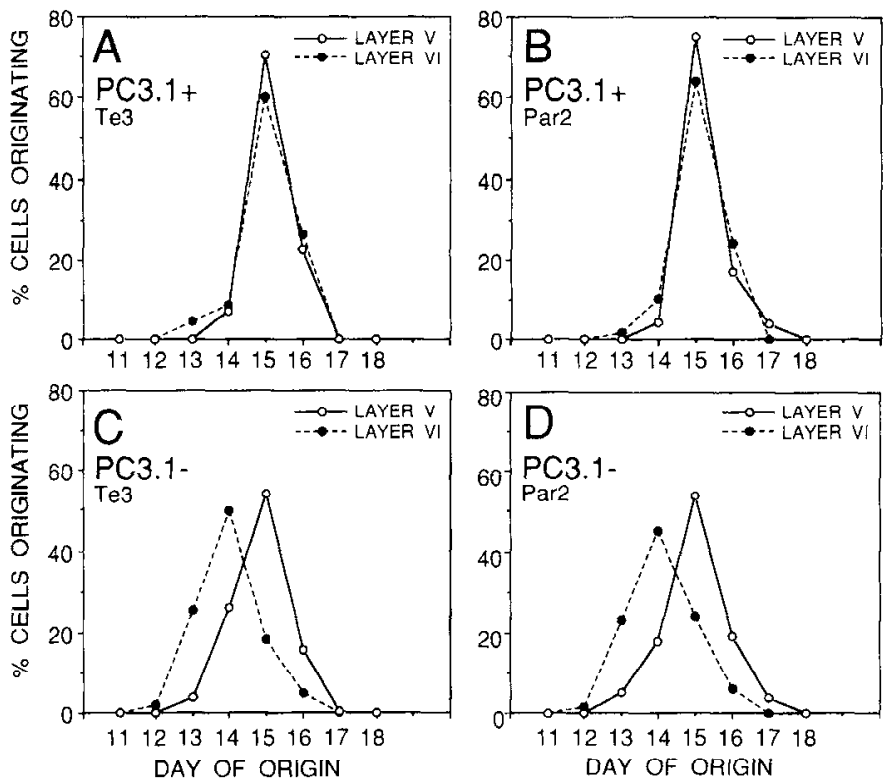

Figure 8. Time of generation of PC3.1-positive $(A$ and $B)$ and -negative $(C$ and $D$ ) neurons in layers V and VI. $A$ and $C$, Te3. $B$ and $D$, Par2. Source data for Te3 are shown in Tables 3 and 4 . The proportion of neurons originating in Par2 was calculated in a similar way as that for Te3. Since the density of PC3.1-positive neurons in layer V of Par2 was low (see Table 2), about twice as many sections were examined for $\operatorname{Par} 2$ as for $\mathrm{Te} 3$ in each injection group.

PC3.1-positive neurons are cogenerated during a more restricted period than are PC3.1-negative neurons, which should represent more diverse phenotypic identities in that layer.

Several lines of evidence suggest there being an intimate correlation between the time of generation of cortical neurons and their morphological identities. (1) In the reeler mutant mouse, although migration of young cortical neurons is disrupted and thus the postmigratory positions of neurons are abnormal, corresponding cell classes are still generated in the same sequence (Caviness, 1982). (2) The neuronal migration is abnormal in rats exposed to $\mathrm{x}$-rays during their fetal stage. Even in these animals, at least certain numbers of corticospinal neurons were generated appropriately (Jensen and Killackey, 1984). (3) According to recent reports, albeit from separate laboratories, the corticocortical and corticotectal neurons in the rat visual cortex may be generated during rather different embryonic days (Miller 1985, 1988b; Contamina and Boada, 1992). Despite this circumstantial support for a strict phenotype-birthday correlation, however, it is not yet fully known which kinds of morphological and molecular phenotypes are actually correlated with the time of generation. Previous studies have revealed that various neurotransmitter phenotypes of cortical neurons are not related to their time of generation (Cavanagh and Parnavelas, 1988, 1989, 1990; Miller, 1988b, 1992; Peduzzi, 1988). Neocortical GABAergic neurons in the rat, for example, are generated throughout the entire period of cortical neurogenesis (Miller, 1985, 1988b; Fairen et al., 1986). None of the subtypes of GABAergic neurons classified according to various morphological characteristics (e.g., shape and size of cell body, pattern of dendritic arborization) have been correlated with distinct birthdays (Cobas and Fairen, 1988). Furthermore, it has been demonstrated that both typical and atypically oriented pyramidal neurons are generated concurrently in an inside-out sequence (Miller, 1988a). In the pres-
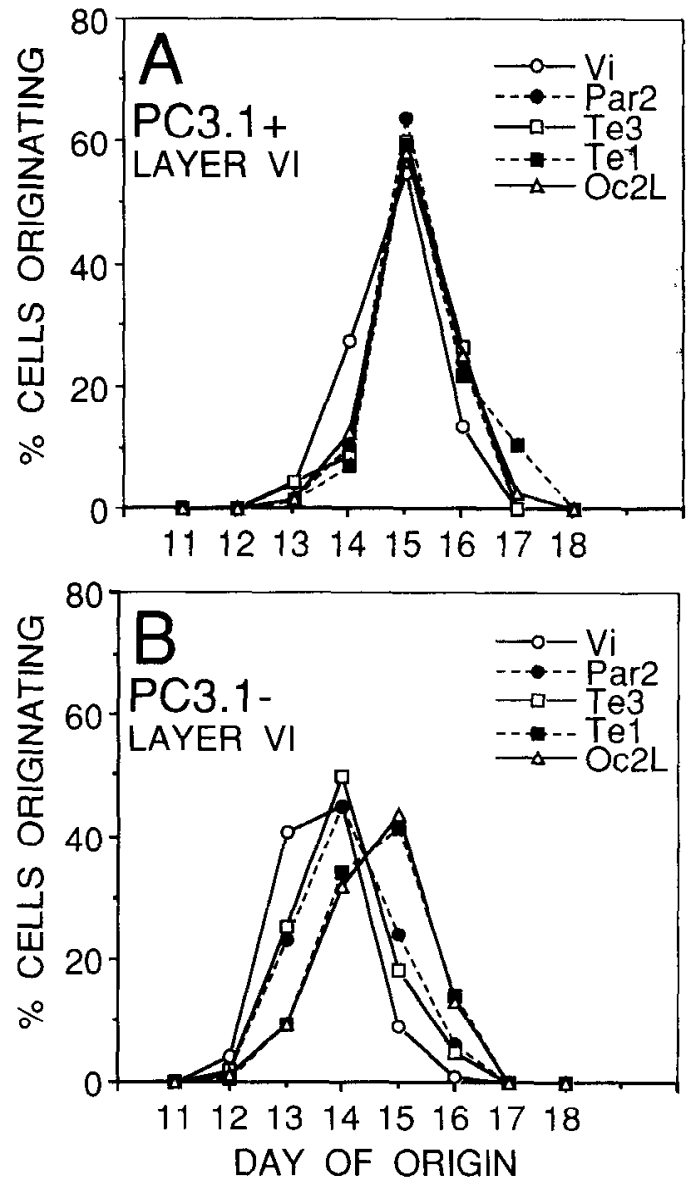

Figure 9. Time of generation of PC3.1-positive $(A)$ and -negative $(B)$ neurons in layer VI of five different lateral neocortical areas. Data were obtained in a similar way as that for 'Ie3 ('Iables 3,4) except that PC3.1positive neurons in $\mathrm{Vi}$ were examined in vertical strips $0.56 \mathrm{~mm}$ wide.

ent study, we have provided convincing evidence for a strict linkage between the time of generation of cortical neurons and their certain phenotypic identity by using the specific molecular marker PC3.1. Although physiological functions of the PC3.1 antigen are not yet known, there is evidence that it is a $29 \mathrm{kDa}$ protein with an amino acid sequence that has not been reported thus far (Arimatsu et al., 1992a; Y. Hatanaka, Y. Uratani, K. Takaguchi-Hayashi, A. Omori, K. Satoh, M. Miyamoto, and $Y$. Arimatsu, unpublished observations).

Although PC3.1-positive neurons in layer $\mathrm{V}$ represent only about $10 \%$ of the total PC3.1-positive neurons in Par2, those in Te 3 represent about $30 \%$ of the total. Thus, it seems unlikely that the apparent cogeneration of PC3.1-positive neurons in layer $\mathrm{V}$ with those in layer VI was derived from various kinds of "fluctuation" or "inaccuracy" in the mechanism regulating the formation of the inside-out laminar structure. It is, however, not known what is the way by which fractions of a single population that are generated concurrently are delivered to separate layers.

\section{Cogeneration of neocortical PC3.1-positive neurons across widespread areas}

Another striking finding of the present study is the cogencration of PC3.1-positive neurons in tangentially widespread cortical regions. Previous ${ }^{3} \mathrm{H}$-thymidine birth-dating studies have revealed broad neurogenetic gradients along rostral-to-caudal and 
ventral-to-dorsal axes in the rodent neocortex. Thus, neurons in a particular lamina tend to be generated earlier in rostral and ventral regions than in caudal and dorsal ones, respectively (Gardette et al., 1982; Smart and Smart, 1982; Miller, 1987; Bayer and Altman, 1991a). However, the tangential neurogenetic gradients should not be complete enough to include all the neocortical neurons. We show in the present study that the vast majority of PC3.1-positive neurons in layer VI are cogenerated at E15, irrespective of their tangential locations. This is in contrast with the observation that PC3.1-negative neurons, representing the major portion of neurons in the same layer, showed tangential neurogenetic gradients.

According to a widely accepted assumption, most if not all young cortical neurons migrate radially, either strictly or through a modified way, from the ventricular zone to their final destination (Rakic, 1988; Misson et al., 1991). If this is applicable for both PC3.1-positive and-negative neurons, the vast majority of PC3.1-positive neurons in layer VI of the rostral and ventral areas (Par2, Te3) are likely to be cogenerated at E15 together with the majority of PC3.1-negative neurons in layer $\mathrm{V}$, and thus the migratory movement of these two populations should be different along the radial axis. On the other hand, PC.3.1positive neurons in layer VI of the more caudal and dorsal areas (Te 1, Oc2L) are likely to be cogenerated at E15 with the majority of PC3.1-negative neurons in the same layer and might comigrate toward their final positions. Thus, there might be certain kinds of tangential heterogeneity that are involved in the migration of PC3.1-positive neurons.

It might also be possible that most of the presumptive PC3.1positive layer VI neurons are generated in a restricted sector of the ventricular zone and migrate more extensively in tangential directions than the presumptive PC3.1-negative neurons. The results of recent lineage tracing experiments using retroviral vectors or an embryonic stem cell line as a tracer showed that some immature neurons indeed migrate across widespread cortical areas (Austin and Cepko, 1990; Nakatsuji ct al., 1991; Walsh and Cepko, 1992, 1993). With sequential ${ }^{3} \mathrm{H}$-thymidine autoradiography, Bayer et al. (1991) suggested the presence of a prominent migratory path, that is, lateral cortical stream, followed by neurons migrating to the lateral and ventrolateral cortical plate. Furthermore, tangential dispersion of fluorescently labeled cells was directly observed in an explant of developing cerebral cortex using time-lapse confocal microscopy, although their exact cell type (e.g., neuronal or glial) was not known (O'Rourke et al., 1992; Fishell et al., 1993). When considering the recent report that both radial mosaicism and tangential cell migration contribute to neocortical development (Tan and Breen, 1993), it would be of great interest to examine whether or not PC3.1-positive neurons represent a specific population that migrate extensively toward tangential directions. Whether or not extensive tangential migration of presumptive PC3.1-positive neurons occurs, we would still conclude that the developing cortical anlage is not homogeneous along the tangential axes in the mechanism of neocortical histogenesis.

\section{Generation of PC3.1-positive neurons in $\mathrm{Cl}$ and $\mathrm{En}$}

The present study demonstrates that the majority of PC3.1positive neurons in $\mathrm{Cl}$ and those in $\mathrm{En}$ (DEn $+\mathrm{VEn}$ ) were generated at E14 and E13-E14, respectively, at least at the level examined. This is in contrast with the cogeneration at E15 of neocortical PC. 3.1-positive neurons across widespread locations. The time of origin of $\mathrm{PC} 3.1$-positive neurons in $\mathrm{Cl}$ and

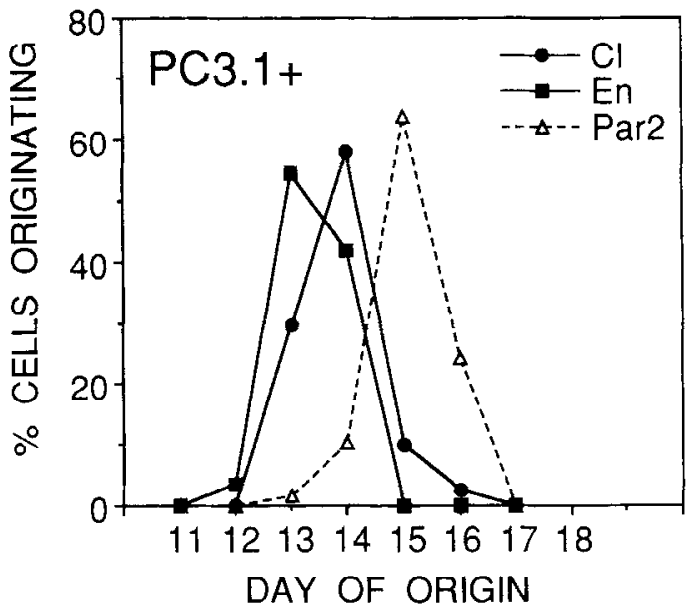

Figure 10. Time of generation of $\mathrm{PC} 3.1$-positive neurons in $\mathrm{Cl}$ and En. PC3. 1-positive neurons in $\mathrm{Cl}$ and $\mathrm{En}(=\mathrm{DEn}+\mathrm{VEn})$ were examined for heavy ${ }^{3} \mathrm{H}$-thymidine labeling in four (E1 1, E I 7) or eight (E12-E16) sections from each injection group between bregma $-0.92 \mathrm{~mm}$ and $-1.30 \mathrm{~mm}$ (Paxinos and Watson, 1986). At this level (approximate location is shown in Fig. 6), $102.7 \pm 4.4$ and $88.8 \pm 3.6$ (both mean \pm SEM, $n=48$ ) PC3.I-positive neurons were found in $\mathrm{Cl}$ and En, respectively, in one side of each section. Values for Par2 are also shown as a reference.

of those in En are in good agreement with the reported birthdays of neurons treated as a single cell population (Bayer and Altman, 1991b). The time of generation of the PC3.1-positive neurons in $\mathrm{Cl}$ and En being earlier than that in the neocortex indicates that these extraneocortical neurons are developmentally distinct from the neocortical ones.

Previously, we reported that PC3.1-positive neurons were present just outside DEn (Arimatsu et al., 1992a). In the present study, we examined the exact localization of PC3.1-positive neurons in the portion deep to the piriform cortex by comparing side by side the adjacent sections stained with PC 3.1 and cresyl violet, respectively, and confirmed that the central core of DEn was mostly devoid of PC3.1-positive neurons. We found, however, that the majority of PC3.1-positive neurons were located within the lateral portion of DEn in addition to those outside the nucleus corresponding to VEn (deOlmes et al., 1985; see Fig. $4 A, B$ ). It is thus evident that DEn can be divided into two distinct subregions with or without PC3.1-positive neurons. In this connection, it may be important to note that DEn was reported to be a heterogeneous nucleus with respect to its afferent projections (Luskin and Price, 1983). A recent study on the distribution of phosphatase inhibitor-1-immunoreactive neurons has also demonstrated that the lateral and medial sectors of the nucleus were distinct (Gustafson et al., 1991). It is of great interest that the distribution pattern of PC3.1-positive neurons was strikingly similar to that of phosphatase inhibitor1-immunoreactive neurons in the regions of the lateral neocortex, $\mathrm{Cl}$ and En.

\section{Implication for neocortical development}

Recently, we demonstrated the selective appearance of PC3.1positive neurons in cultures derived from a lateral, but not dorsal, sector of neocortical tissue at E12 or later, suggesting that some kind of neocortical regional specification occurs very early along the dorsal-ventral axis (Arimatsu et al., 1992a). The tangential heterogeneity of the developing neocortex predicted from the cogeneration of PC3.1-positive neurons further sup- 
ports the concept of early regional specification within the neocortex.

Although it may be premature to discuss the timing and factors that contributc to the cell fate determination of PC3.1positive neurons, it is important to note that it is now possible to test, both in vivo and in vitro. whether some of the newly postmitotic neurons at E 15 are already committed to the specific molecular phenotype. Using a heterochronic transplantation technique, McConnell and Kaznowski (1991) suggested that cortical progenitor cells in the ferret are initially multipotent but are commilted to a specific laminar fate by environmental factors acting at around their final round of cell division. Based on the strict birthday cell fate relationship demonstrated in the present study, it is tempting to speculate that the commitment of cells to the PC3.1 phenotype occurs around E15, depending on their interactions with their environments. However, it is also possible that such a commitment occurs earlier in some progenitor cells in the lateral sector of the ventricular zone. These two alternative scenarios can be examined experimentally, and the resultant information would shed new light on the mechanism of neocortical development.

\section{References}

Angevine JB, Sidman RL (1961) Autoradiographic study of cell migration during histogenesis of cerebral corlex of the mouse. Nature 192:766-768.

Arimatsu Y, Miyamoto M, Nihonmatsu I, Hirata K, Uratani Y, Hatanaka Y, Takiguchi-Hayashi K (1992a) Early regional specification for a molecular neuronal phenotype in the rat neocortex. Proc Natl Acad Sci USA 89:8879-8883.

Arimatsu Y. Nihonmatsu I, Hirata K, Takiguchi-Hayashi K, Miyamoto M (1992b) Generation of neocortical layer 6 neurons with regionspecific PC3 I antigen in the rat. Neurosci Res [Suppl] 17:S161.

Austin CP, Cepko CL (1990) Cellular migration patterns in the developing mouse cerebral cortex. Development 110:713-732.

Baycr SA, Altman J (1991a) Neocortical development. New York: Raven.

Bayer SA, Altman J (1991b) Development of the endopiriform nucleus and the claustrum in the rat brain. Neuroscience 45:391-412.

Bayer SA. Altman J, Russo RJ, Dai X, Simmons JA (1991) Cell migration in the rat embryonic neocortex. J Comp Neurol 307:499516.

Berry M, Rogers AW (1965) The migration of neuroblasts in the developing cerebral cortex. J Anat 99:691-709.

Bruckner G, Mares V, Biesold D (1976) Neurogenesis in the visual system of the rat. An autoradiographic investigation. J Comp Neurol $166: 245-256$

Bueno-López JL, Reblet C, López-Medina A, Gómez-Urquijo SM, Grandes P, Gondra J, Hennequet L (1991) Targets and laminar distribution of projection neurons with 'inverted' morphology in rabbit cortex. Eur J Neurosci 3:415-430.

Cavanagh ME, Parnavelas JG (1988) Development of somatostatin immunoreactive neurons in the rat occipital cortex: a combined immunocytochemical-autoradiographic study. J Comp Neurol 268:112.

Cavanagh ME, Parnavelas JG (1989) Development of vasoactive intestinal-polypeptide immunoreactive neurons in the rat occipital cortex. A combined immunocytochemical-autoradiographic study. J Comp Neurol 284:637-645.

Cavanagh ME, Parnavelas JG (1990) Development of neuropcptide Y (NPY) immunoreactive neurons in the rat occipital cortex: a combined immunocytochemical-autoradiographic study. J Comp Neurol 297:553-563.

Caviness VS Jr (1982) Neocortical histogenesis in normal and reeler mice: a developmental study based on $\left[{ }^{3} \mathrm{H}\right]$ thymidine autoradiography. Dev Brain Res 4:293-302

Cubas A, Fairen A (1988) GABAergic neurons of different morphological classes are cogenerated in the mouse barrcl cortex. J Neurocytol 17:511-519.

Contamina P. Boada E (1992) Time of origin of cortico-collicular projection neurons in the rat visual cortex. J Comp Neurol 323:570576.

deOlmes J, Alheide GF, Beltramino CA (1985) Amygdala. In: The rat nervous system, $V_{o l} l$, forebrain and midbrain (Paxinos $G$, ed), pp 223-334. Sydney: Academic.

Fairen A Cobas A. Fonseca M (1986) Times of generation of glutamic acid decarboxylase immunoreactive neurons in mouse somatosensory cortex. J Comp Neurol 251:67-83.

Fishell G, Mason CA, Hatten ME (1993) Dispersion of neural progenitors within the germinal zones of the forebrain. Nature 362:636638.

Gardette R, Courtoris M, Bisconte JC (1982) Prenatal development of mouse central nervous structures: time of origin and gradients of neuronal production. A radioautographic study. J Hirnforsch 23:415431.

Gilbert CD (1983) Microcircuitry of the visual cortex. Annu Rev Neurosei $6: 217-247$

Gustafson EL, Girault J-A, Hemmings HC Jr, Nairn AC, Greengard P (1991) Immunocytochemical localization of phosphatase inhibitor-1 in rat brain. J Comp Neurol 310:17-188.

Hicks SP, D'Amato CJ (1968) Cell migration to the isocortex in the rat. Anat Rec 160:619-634.

Jackson CA, Peduzzi JD, Hickey TL (1989) Visual cortex development in the ferret. I. Genesis and migration of visual cortical neurons. J Neurosci 9:1242-1253.

Jacobson M (1991) Developmental neurobiology, 3d ed. New York: Plenum.

Jensen KF, Killackey HP (1984) Subcortical projections from ectopic neocortical neurons. Proc Natl Acad Sci USA 81:964-968.

Lent R, Hedin-Pereira C, Menezes JRL, Jhaveri S (1990) Neurogenesis and development of callosal and intracortical connections in the hamster. Neuroscience 38:21-37.

Luskin MB, Price JL (1983) The topographic organization of associational fibers of the olfactory system in the rat, including centrifugal fibers to the olfactory bulb. J Comp Neurol 216:264-291.

Luskin MB, Shatz CJ (1985) Neurogenesis of the cat's primary visual cortex. J Comp Neurol 242:611-631.

McConnell SK (1988) Development and decision-making in the mammalian cerebral cortex. Brain Res Rev 13:1-23.

McConnell SK, Kaznowski CE (1991) Cell cycle dependence of laminar determination in developing neocortex. Science 254 28 2-285.

Miller MW (1985) Cogeneration of retrogradely labelled corticocortical projection and GABA-immunoreactive local circuit neurons in cercbral cortex. Dev Brain Res 23:187-192.

Miller MW (1987) Effect of prenatal exposure to ethanol on the distribution and time of origin of corticospinal neurons in the rat. $J$ Comp Neurol 257:372-382.

Miller MW (1988a) Maturation of rat visual cortex. IV. The generation, migration. morphogenesis and connectivity of atypically oriented pyramidal neurons. J Comp Neurol 274:387-405.

Miller MW (1988b) Development of projection and local circuit neurons in ncocortex. In: Cerebral cortex, Vol 7 (Jones EG, Peters A, eds), pp 133-175. New York: Plenum.

Miller MW (1992) Migration of peptide-immunoreactive local circuit neurons to rat cingulate cortex. Cereb Cortex $2: 444-455$

Misson J-P, Austin CP, Takahashi T, Cepko CL, Caviness VS Jr (1991) The alignment of migrating neural cells in relation to the murine neopallial radial glial fiber system. Cereb Cortex 1:221 229.

Nakatsuji N, Kadokawa Y, Suemori H (1991) Radial columnar patches in the chimeric cerebral cortex visualized by use of mouse embryonic stem cells expressing $\beta$-galactosidase. Dev Growth Differ 33: $571-578$.

O'Rourke NA, Dailey ME, Smith SJ, McConnell SK (1992) Diverse migratory pathways in the developing cerebral cortex. Science 258: 299-302.

Paxinos G, Watson C (1986) The rat brain in stereotaxic coordinates, $2 \mathrm{~d}$ ed. North Ryde: Academic.

Peduzzi JD (1988) Genesis of GABA-immunoreactive neurons in the ferret visual cortex. J Neurosci 8:920-931.

Rakic P (1974) Neurons in rhesus monkey visual cortex: systematic relation between time of origin and eventual disposition. Science 183: $425-427$.

Rakic P (1988) Specification of cerebral cortical areas. Science 241: 170-176.

Shinada M, Langman J (1970) Cell proliferation, migration and dif- 
ferentiation in the cerebral cortex of the golden hamster. J Comp Neurol 139:227-244.

Sidman RL (1970) Autoradiographic methods and principles for study of the nervous system with thymidine- $\mathrm{H}^{3}$. In: Contemporary research methods in neuroanatomy (Nauta WJH, Ebbesson SOE, eds), pp 252274. New York: Springer.

Smart IHM, Smart M (1982) Growth patterns in the lateral wall of the mouse telencephalon. I. Autoradiographic studies of the histogenesis of the isocortex and adjacent areas. J Anat 134:273-298.

Tan S-S, Breen S (1993) Radial mosaicism and tangential cell dispersion both contribute to mouse neocortical development. Nature 362:638-640.

Wacchter RV, Jaensch B (1972) Generation times of the matrix cells during embryonic brain development: an autoradiographic study in rats. Brain Res 46:235-250.
Walsh C, Cepko CL (1992) Widespread dispersion of neuronal clones across functional regions of the cerebral cortex. Science 255:434-440. Walsh C, Cepko CL (1993) Clonal dispersion in proliferative layers of developing cerebral cortex. Nature 362:632-635.

Zilles K (1985) The cortex of the rat. A stereotaxic atlas. Berlin: Springer.

Zilles K (1990) Anatomy of the neocortex: cytoarchitecture and myeloarchitecture. In: The cerebral cortex of the rat (Kolb B, Tees RC, eds), pp 77-112. Cambridge, MA: MIT Press.

Zilles K, Wree A, Dausch N-D (1990) Anatomy of the neocortex: neurochemical organization. In: The cerebral cortex of the rat (Kolb B, Tees RC, eds), pp 113-150. Cambridge, MA: MIT Press. 